\title{
NIBP impacts on the expression of E-cadherin, CD44 and vimentin in colon cancer via the NF- $\kappa B$ pathway
}

\author{
CHUN-YAN XU, MENG-BIN QIN, LIN TAN, SHI-QUAN LIU and JIE-AN HUANG \\ Department of Gastroenterology, The First Affiliated Hospital of Guangxi Medical University, \\ Nanning, Guangxi 530021, P.R. China
}

Received May 12, 2015; Accepted April 11, 2016

DOI: $10.3892 / \mathrm{mmr} .2016 .5165$

\begin{abstract}
NIBP, a novel nuclear factor- $\kappa \mathrm{B}$ (NF- $\mathrm{kB})$-inducing kinase (NIK) and IкB kinase $\beta$ (IKK $\beta$ ) binding protein, directly interacts with NIK and IKK $\beta$, and acts as the 'bridge' of the NF- $\mathrm{KB}$ classical and alternative signaling pathways. However, its influence on epithelial-mesenchymal transition markers in colon cancer remains to be fully elucidated. The aim of the present study was to investigate the roles of NIBP impacting on the expression of E-cadherin, CD44 and vimentin. In the present study, the associations between NIBP and E-cadherin, CD44 and vimentin in clinical samples were analyzed by making pairwise comparisons between normal colon tissue, non-metastatic colon cancer tissue and metastatic colon cancer tissue. In in vitro experiments, after changing the expression of NIBP in cells, the protein expression levels of CD44, vimentin, E-cadherin were analyzed by western blot analysis. The results revealed that the protein expression levels of NIBP, CD44 and vimentin were markedly increased, and E-cadherin was markedly decreased, in metastatic colon cancer tissue compared with normal colon tissue and non-metastatic colon cancer tissue. Upregulation of NIBP expression decreased the levels of E-cadherin, whereas the downregulation of NIBP increased E-cadherin levels, while no significant differences were observed in the levels of CD44 and vimentin. In addition, cells that were treated with the NF- $\kappa B$ inhibitor, pyrrolidine dithiocarbamate (PDTC), also tended to exhibit increased levels of CD44 and vimentin expression in the NIBP upregulated expression group (29-NIBP group) compared with the mock group, whereas the expression levels of E-cadherin, CD44 and vimentin were similar in the NIBP downregulated expression group (116-NIBPmir group) and the HCT116 blank control group (116-mock group) on treatment
\end{abstract}

Correspondence to: Professor Jie-An Huang, Department of Gastroenterology, The First Affiliated Hospital of Guangxi Medical University, 6 Shuangyong Road, Nanning, Guangxi 530021, P.R. China

E-mail: 1404991727@qq.com

Key words: NIK and IKK $\beta$ binding protein, E-cadherin, colon cancer, CD44, vimentin of the cells with tumor necrosis factor- $\alpha$. These findings indicated that NIBP, E-cadherin, CD44 and vimentin are possibly associated with metastasis in colon cancer. When the NF- $\mathrm{KB}$ pathway is not subjected to any interventions, NIBP may predominantly regulate the NF- $\mathrm{\kappa B}$ classical pathway, rather than the alternative pathway. When the classical pathway was completely inhibited, NIBP was able to activate the NF- $\mathrm{KB}$ alternative pathway. NIBP is therefore necessary for the interaction between the NF- $\kappa \mathrm{B}$ classical and alternative pathways. In conclusion, NIBP impacts on the expression levels of E-cadherin, CD44 and vimentin via the NF- $\mathrm{KB}$ classical and alternative pathways. Therapeutic regimens for patients with colorectal cancer may comprise NIBP inhibitors in the future.

\section{Introduction}

Cancer is a major cause of mortality, and colorectal cancer (CRC) is the third most common cancer in men and women worldwide, representing a leading cause of cancer-associated mortality (1). The majority of human cancer-associated deaths are linked with metastasis. Metastasis is a complex process, involving the spread of malignant tumor cells from a primary tumor site to a secondary organ, and colonization of the distant organ.

The metastasis of CRC results from the interactions among a number of genetic and environmental factors. Multiple signal transduction pathways are involved in the process, including the nuclear factor- $\kappa \mathrm{B}(\mathrm{NF}-\kappa \mathrm{B})(2,3)$ and the focal adhesion kinase (FAK) (4) pathways, and so forth. The NF-kB pathway exerts an important role in the process of tumor invasion and metastasis. The NF- $\mathrm{kB}$ family of transcription factors consists of five members: p65 (or RelA), RelB, c-Rel, NF- $\mathrm{BB} 1$ (or p105; a precursor of $\mathrm{p} 50$ ) and NF- $\mathrm{kB} 2$ (or p100; a precursor of p52) (5-7). To date, two principal pathways for NF- $\mathrm{BB}$ activation have been characterized: A classical and an alternative pathway $(6,8)$.

NIBP, a novel NF- $\kappa B$-inducing kinase (NIK) and IкB kinase $\beta$ (IKK $\beta$ ) binding protein, directly interacts with NIK and IKK $\beta$, and is required for cytokine-induced NF- $\kappa \mathrm{B}$ activation. The overexpression of NIBP increased the expression of IKK $\beta$ and NIK $(9,10)$. The activated IKK complex phosphorylates $\mathrm{I} \kappa \mathrm{B}$ molecules to induce their ubiquitination and degradation, resulting in the translocation of NF- $\mathrm{KB}$ dimers (predominantly p65/p50) to the nucleus and the transcriptional 
activation of specific target genes. This pathway is termed the $\mathrm{NF}-\kappa \mathrm{B}$ classical pathway. In the $\mathrm{NF}-\kappa \mathrm{B}$ alternative pathway, NIK activates I $\kappa$ B kinase $\alpha(\mathrm{IKK}-\alpha)$ to induce the processing of p100, generating the p52 subunit, which leads to nuclear translocation of RelB/p52 dimers to regulate specific target gene expression. At present, studies of NIBP have largely concentrated on nerve cells, and the protein has been studied only infrequently in tumor cells. A previous study by our laboratory identified that there was a certain basal expression level of NIBP in colon cancer cells (11). Therefore, it was hypothesized that NIBP may affect the invasive and metastatic abilities of tumor cells by regulating the $N F-\kappa B$ signaling pathway.

E-cadherin and vimentin are important markers of the epithelial-to-mesenchymal transition (EMT). EMT is a critical process by which epithelial cells lose their polarity, and are converted into the mesenchymal phenotype. The hallmarks of EMT are a loss of epithelial cell markers, including E-cadherin, and an increased expression of mesenchymal markers, including vimentin and fibronectin $(12,13)$. EMT enhances the ability of cancer cells to migrate to, invade, increase apoptosis in and degrade cells of the extracellular matrix. It is crucial for a variety of original and early metastases of tumor cells. In recent years, a burgeoning body of evidence has identified that EMT exerts an important role in the invasion and metastasis of colon cancer $(14,15)$.

Previous studies have shown that, on activation of the $\mathrm{NF}-\kappa \mathrm{B}$ pathway, the expression levels of E-cadherin decreased, whereas that of vimentin increased $(16,17)$. In the light of these results, it was hypothesized that NIBP may exert an influence on the expression levels of E-cadherin, CD44 and vimentin in CRC cells through the NF- $\mathrm{BB}$ classical and alternative pathways. In the present study, the correlation between NIBP, E-cadherin, CD44, vimentin and tumor progression in patients with CRC was examined. To investigate this hypothesis, gene transfection experiments were used to control the expression of NIBP in order to observe any influence on the expression of E-cadherin, CD44 and vimentin in colon cancer cells.

\section{Materials and methods}

Patients and tissues. Randomly selected paired tissues of CRC and corresponding normal tissues were obtained from patients $(n=114)$ who underwent surgical resection at the First Affiliated Hospital of Guangxi Medical University (Guangxi, China) between March and October 2013. Written informed consent was obtained from each patient prior to surgery and the study protocol was approved by the Institutional Review Board for Human Genetic and Genomic Research of the First Affiliated Hospital of Guangxi Medical University. Every sample had undergone an immunohistochemical analysis in a previous study (11).

Cell culture and lentivirus infection. HT29 and HCT116 cells were obtained from Shanghai R\&S Biotechnology Co. (Shanghai, China). HT29 is a cell line that expresses small quantities of the NIBP protein, whereas HCT116 cells express higher levels. All cell lines were cultured in Dulbecco's modified Eagle's medium (Gibco; Thermo Fisher Scientific,
Waltham, MA, USA) with $10 \%$ fetal bovine serum (Excell Bio, Shanghai, China) at $37^{\circ} \mathrm{C}$ under an atmosphere of $5 \% \mathrm{CO}_{2}$.

Groups of cells were used for the various experiments as follows: the non-specific control group (29-NC group) and NIBP upregulated expression group (29-NIBP group) of the HT29 cell line, and the non-specific control group (116-NC group) and NIBP downregulated expression group (116-NIBPmir group) of the HCT116 cell line. The stable NIBP-overexpressing (11) and underexpressing (18) cell lines were transfected and obtained by fluorescence-activated cell sorting in previous studies.

Western blot analysis. Proteins were separated using 10\% sodium dodecyl sulfate-polyacrylamide gel (Beyotime Institute of Biotechnology, Haimen, China) electrophoresis for $1 \mathrm{~h}$ at $100 \mathrm{~V}$, and transferred onto polyvinylidene fluoride membranes (EMD Millipore, Billerica, MA, USA). The membranes were subsequently blocked with non-fat milk [5\% in Tris-buffered saline with Tween-20; TBST (Beijing Solarbio Science \& Technology Co., Ltd., Beijing, China)] buffer at room temperature for $1 \mathrm{~h}$ to block non-specific binding, and were subsequently incubated overnight with antibodies diluting with WB Antibody Diluent (Beyotime Institute of Biotechnology) at $4^{\circ} \mathrm{C}$. Subsequently, conjugated secondary antibodies were incubated for $1 \mathrm{~h}$ at room temperature. Membranes were scanned and analyzed using an Odyssey ${ }^{\circledR}$ CLx Infrared Imaging system (LI-COR Biosciences, Lincoln, NE, USA). Relevant signal intensities were determined using LI-COR imaging software. Rabbit monoclonal anti-glyceraldehyde-3-phosphate dehydrogenase (GAPDH; 1:1,000; cat. no. 2118) and rabbit monoclonal anti-E-cadherin (1:1,000; cat. no. 3195) antibodies were obtained from Cell Signaling Technology (Danvers, MA, USA); rabbit polyclonal anti-vimentin (1:500; cat. no. 10366-1-AP) was obtained from ProteinTech Group, Inc. (Chicago, IL, USA), and rabbit polyclonal anti-CD44 (1:500) was obtained from BIOSS (Beijing, China; cat. no. bs-0521R) and ProteinTech Group, Inc. (cat. no. 15675 1-AP).

Statistical analysis. Each experiment was performed at least three times. Differences between groups and controls were assessed using the Student's t-test and univariate analysis. $\mathrm{P}<0.0167(0.05 / 3)$ was considered to indicate a statistically significant value in the clinical samples. For the in vitro experiments, relative fold changes in protein expression were calculated following normalization against GAPDH; in these cases, ${ }^{*} \mathrm{P}<0.05$ was considered to indicate a statistically significant value.

\section{Results}

The association between NIBP and E-cadherin, CD44, vimentin in clinical samples. In a previous study, every sample had undergone an immunohistochemical analysis to examine the expression levels of NIBP and E-cadherin, CD44 and vimentin (Table I) (19). In the present study, these data were analyzed from another aspect. The pairwise comparisons with normal colon tissue and non-metastatic colon cancer (Table II), normal colon tissue and metastatic colon cancer (Table III), and non-metastatic colon cancer and metastatic colon cancer (Table IV) are shown. 
Table I. Negative and positive cases of NIBP and E-cadherin, CD44 and vimentin protein in clinical samples assessed by immunohistochemistry analysis.

\begin{tabular}{|c|c|c|c|c|c|c|c|c|c|}
\hline \multirow[b]{2}{*}{ Tissue } & \multirow{2}{*}{$\begin{array}{l}\text { No. of } \\
\text { cases }\end{array}$} & \multicolumn{2}{|c|}{ NIBP } & \multicolumn{2}{|c|}{ CD44 } & \multicolumn{2}{|c|}{ Vimentin } & \multicolumn{2}{|c|}{ E-cadherin } \\
\hline & & - & + & - & + & - & + & - & + \\
\hline Normal colon & 50 & 40 & 10 & 37 & 13 & 42 & 8 & 9 & 41 \\
\hline $\begin{array}{l}\text { Non-metastatic } \\
\text { colon cancer }\end{array}$ & 63 & 33 & 30 & 35 & 28 & 40 & 23 & 15 & 48 \\
\hline Metastatic colon cancer & 51 & 14 & 37 & 17 & 34 & 19 & 32 & 27 & 24 \\
\hline
\end{tabular}

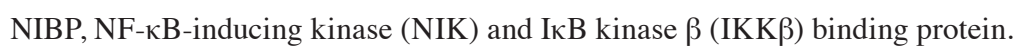

Table II. Expression of NIBP and CD44, vimentin and E-cadherin in normal colon tissue and non-metastatic colon cancer.

\begin{tabular}{|c|c|c|c|c|c|c|c|c|c|c|c|c|c|}
\hline \multirow[b]{2}{*}{ Tissue } & \multirow{2}{*}{$\begin{array}{l}\text { No. of } \\
\text { cases }\end{array}$} & \multicolumn{3}{|c|}{ NIBP } & \multicolumn{3}{|c|}{ CD44 } & \multicolumn{3}{|c|}{ Vimentin } & \multicolumn{3}{|c|}{ E-cadherin } \\
\hline & & - & + & $\mathrm{P}$ & - & + & $\mathrm{P}$ & - & + & $\mathrm{P}$ & - & + & $\mathrm{P}$ \\
\hline Normal colon & 50 & 40 & 10 & & 37 & 13 & & 42 & 8 & & 9 & 41 & \\
\hline $\begin{array}{l}\text { Non-metastatic } \\
\text { colon cancer }\end{array}$ & 63 & 33 & 30 & 0.002 & 35 & 28 & 0.043 & 40 & 23 & 0.015 & 15 & 48 & 0.453 \\
\hline
\end{tabular}

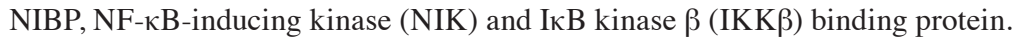

Table III. Expression of NIBP and CD44, vimentin and E-cadherin in normal colon tissue and metastatic colon cancer.

\begin{tabular}{|c|c|c|c|c|c|c|c|c|c|c|c|c|c|}
\hline \multirow[b]{2}{*}{ Tissue } & \multirow{2}{*}{$\begin{array}{c}\text { No. of } \\
\text { cases }\end{array}$} & \multicolumn{3}{|c|}{ NIBP } & \multicolumn{3}{|c|}{ CD44 } & \multicolumn{3}{|c|}{ Vimentin } & \multicolumn{3}{|c|}{ E-cadherin } \\
\hline & & - & + & $\mathrm{P}$ & - & + & $\mathrm{P}$ & - & + & $\mathrm{P}$ & - & + & $\mathrm{P}$ \\
\hline Normal colon & 50 & 40 & 10 & $<0.001$ & 37 & 13 & $<0.001$ & 42 & 8 & $<0.001$ & 9 & 41 & $<0.001$ \\
\hline $\begin{array}{l}\text { Metastatic } \\
\text { colon cancer }\end{array}$ & 51 & 14 & 37 & & 17 & 34 & & 19 & 32 & & 27 & 24 & \\
\hline
\end{tabular}

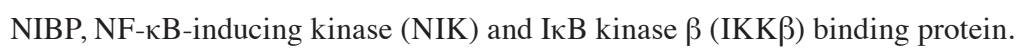

Table IV. Expression of NIBP and CD44, vimentin and E-cadherin in non-metastatic colon cancer and metastatic colon cancer.

\begin{tabular}{|c|c|c|c|c|c|c|c|c|c|c|c|c|c|}
\hline \multirow[b]{2}{*}{ Tissue } & \multirow{2}{*}{$\begin{array}{l}\text { No. of } \\
\text { cases }\end{array}$} & \multicolumn{3}{|c|}{ NIBP } & \multicolumn{3}{|c|}{ CD44 } & \multicolumn{3}{|c|}{ Vimentin } & \multicolumn{3}{|c|}{ E-cadherin } \\
\hline & & - & + & $\mathrm{P}$ & - & + & $\mathrm{P}$ & - & + & $\mathrm{P}$ & - & + & $\mathrm{P}$ \\
\hline $\begin{array}{l}\text { Metastatic colon } \\
\text { cancer }\end{array}$ & 51 & 14 & 37 & 0.007 & 17 & 34 & 0.018 & 19 & 32 & 0.005 & 27 & 24 & 0.001 \\
\hline $\begin{array}{l}\text { Non-metastatic } \\
\text { colon cancer }\end{array}$ & 63 & 33 & 30 & & 35 & 28 & & 40 & 23 & & 15 & 48 & \\
\hline
\end{tabular}

$\mathrm{P}<0.0167(0.05 / 3)$ was considered statistically significant. NIBP, NF- $\kappa B$-inducing kinase (NIK) and IкB kinase $\beta$ (IKK $\beta$ ) binding protein.

These results demonstrated that the levels of NIBP, CD44 and vimentin significantly increased, and that of E-cadherin significantly decreased, in metastatic colon cancer compared with normal colon tissue and non-metastatic colon cancer, indicating that NIBP, E-cadherin, CD44 and vimentin are possibly associated with metastasis in colon cancer. However, it remained to be elucidated whether NIBP could impact on the expression levels of E-cadherin, CD44 and vimentin. 

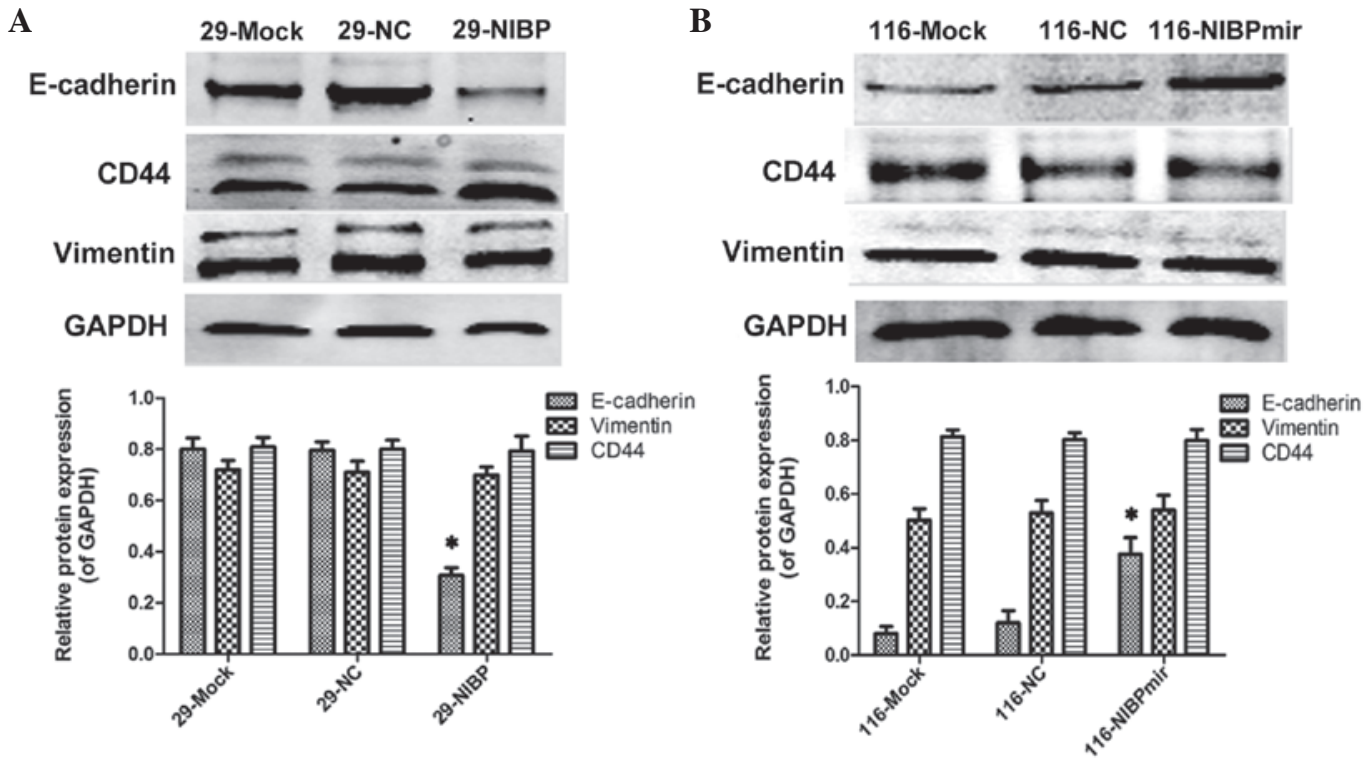

Figure 1. Influence of NIBP on the expression of epithelial-to-mesenchymal-transition-associated markers. (A) Western blot analysis of E-cadherin, CD44 and vimentin in the 29-mock, 29-NC and 29-NIBP groups, which were conventionally cultured. (B) Western blot analysis of E-cadherin, CD44 and vimentin in the 116-mock, 116-NC and 116-NIBP groups, which were conventionally cultured. GAPDH was used as an internal control for both sets of experiments. The data were analyzed by t-test. All data are presented as the mean \pm standard deviation. " $\mathrm{P}<0.05$ vs. the mock group. GAPDH, glyceraldehyde-3-phosphate dehydrogenase.

The influence of different expression levels of NIBP on expression of E-cadherin, CD44 and vimentin in CRC cell lines. In an in vitro experiment, western blotting was used to assess the expression of CD44, vimentin and E-cadherin protein in the HT29 blank control group (29-mock group), the 29-NC and 29-NIBP groups (Fig. 1A). The identical experiment was performed with the HCT116 blank control group (116-mock group) and the 116-NC and 116-NIBPmir groups (Fig. 1B).

The results revealed that the upregulation of NIBP decreased the levels of E-cadherin, whereas downregulating the expression of NIBP increased E-cadherin. A previous study demonstrated that the activated NF- $\mathrm{kB}$ classical pathway decreased E-cadherin expression $(16,20,21)$. The data in the present study also confirmed that NIBP fulfilled the role of activator in the NF- $\kappa B$ classical pathway (9). On the other hand, no significant differences were observed in the levels of CD44 and vimentin according to the different expression levels of NIBP in the present study (Fig. 1A and B). A previous study demonstrated that activation of the NF- $\mathrm{KB}$ alternative pathway led to an induction of the upregulation of CD44, and EMT contributed to an increased cancer cell invasiveness (22).

Furthermore, other studies revealed that CD44 upregulated the expression of vimentin, whereas knockdown of CD44 decreased the expression of vimentin (23-25). Therefore, the results in the present study suggested that the effects of NIBP are exerted predominantly through the regulation of the NF- $\mathrm{\kappa B}$ classical pathway, rather than the alternative pathway, when the NF- $\mathrm{kB}$ pathway was not subjected to any interventions.

Effects of PDTC on the expression levels of CD44, vimentin and E-cadherin in the NF- $\kappa B$ pathway in HT29 cells. On treating the 29-mock and 29-NIBP groups with PDTC (Fig. 2), an NF- $\mathrm{kB}$ classical pathway inhibitor, the expression levels of CD44 and vimentin tended to increase in 29-NIBP group, whereas that of E-cadherin decreased.
As NIBP is considered to act as the 'bridge' of the NF- $\mathrm{KB}$ classical and alternative pathways (9), it was hypothesized that NIBP may predominantly activate the NF- $\mathrm{BB}$ alternative pathway following the complete inhibition of the classical pathway. Therefore, on treatment of the cells with PDTC, the expression levels of CD44 and vimentin were revealed to be increased in the 29-NIBP group compared with the 29-mock group.

Downregulation of the expression of NIBP disturbs $T N F$ - $\alpha$-induced NF- $\kappa B$ activation in HCT116 cells. The 116-mock and 116-NIBPmir groups were treated with TNF- $\alpha$ (Fig. 3), an NF-kB classical pathway activator, revealing that the expression levels of E-cadherin, CD44 and vimentin were similar between the two groups. Since downregulation of the expression of NIBP increased E-cadherin levels in the HCT116 cell line without treatment with TNF- $\alpha$ (Fig. 1B), this suggested that TNF- $\alpha$ could impact on the NF- $\kappa B$ classical pathway, but was not able to influence the NF- $\kappa B$ alternative pathway when NIBP was silenced in cells, revealing that NIBP acts as the bridge between the NF- $\mathrm{kB}$ classical and alternative pathways.

\section{Discussion}

A major challenge during cancer therapy is metastasis. However, the underlying mechanisms have not been entirely elucidated. Metastasis is one of the fundamental characteristics of malignant tumors, as well as the predominant cause of treatment failure for most types of carcinoma $(26,27)$. EMT is the important biological process, which enables malignant tumor epithelial cells to acquire their migrational and invasive abilities. Furthermore, increasing the expression of vimentin, and decreasing the expression of E-cadherin, are its predominant features $(12,28,29)$. The present study revealed that the expression of vimentin increased significantly, and that of 
(PDTC)
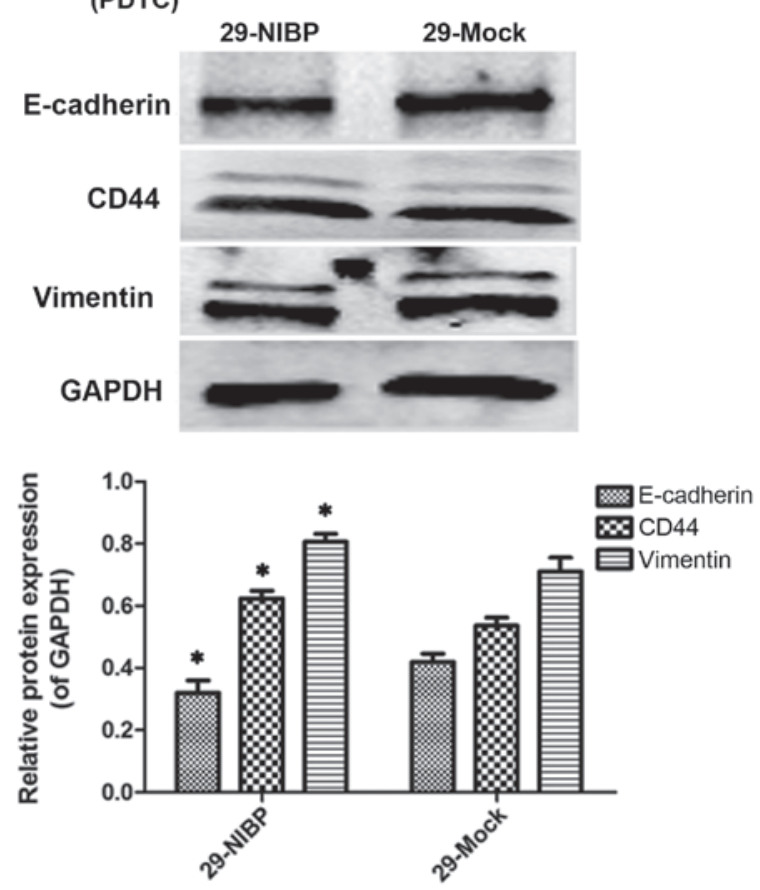

Figure 2. HT29 cells (the 29-mock and 29-NIBP groups) were treated with PDTC $(5 \mu \mathrm{g} / \mathrm{ml})$ for $24 \mathrm{~h}$, and the expression levels of E-cadherin, CD44 and vimentin were analyzed by western blotting. GAPDH served as the loading control. The data were analyzed by t-test. All data are presented as the mean \pm standard deviation. $\mathrm{P}<0.05,29$ NIBP vs. the 29 -mock group. GAPDH, glyceraldehyde-3-phosphate dehydrogenase; PDTC, pyrrolidine dithiocarbamate.

E-cadherin decreased significantly, in colon cancer tissues. It also revealed that E-cadherin and vimentin are closely linked with invasion and metastasis in colon cancer. The results obtained are consistent with those of previously published studies $(30,31)$.

NIBP acts as the 'bridge' of NF- $\mathrm{KB}$ classical and alternative pathways, and NIBP is involved in regulating the classical and alternative pathways. The present study demonstrated showed that there were plentiful quantities of NIBP in metastatic and non-metastatic colon cancer tissues compared with normal tissue, suggesting that NIBP may be involved in the occurrence and development of colon cancer. Therefore, it was surmised that NIBP possibly exerts an important role in impacting on the expression of E-cadherin and vimentin via the NF- $\mathrm{KB}$ classical and alternative pathways in colon cancer cells.

A previous study has shown that the levels of phosphorylated $\mathrm{p} 65$ increased on activation of the NF- $\mathrm{KB}$ classical pathway (32). Subsequently, the phosphorylated p65 was transported into the nucleus to regulate gene transcription, promoting the expression of snail $(33,34)$, one of the important transcription factors associated with EMT, thereby suppressing the expression of E-cadherin. Furthermore, activation of the $\mathrm{NF}-\kappa \mathrm{B}$ alternative pathway led to an increase in the expression of CD44, a stem-cell-surface molecule (35). Vimentin expression decreased when the expression of CD44 was knocked down (25). In order to further confirm that NIBP has a role as an activator of the NF-kB classical pathway (9), HT29 cells were transfected to upregulate NIBP, which demonstrated
(TNF- $\alpha)$

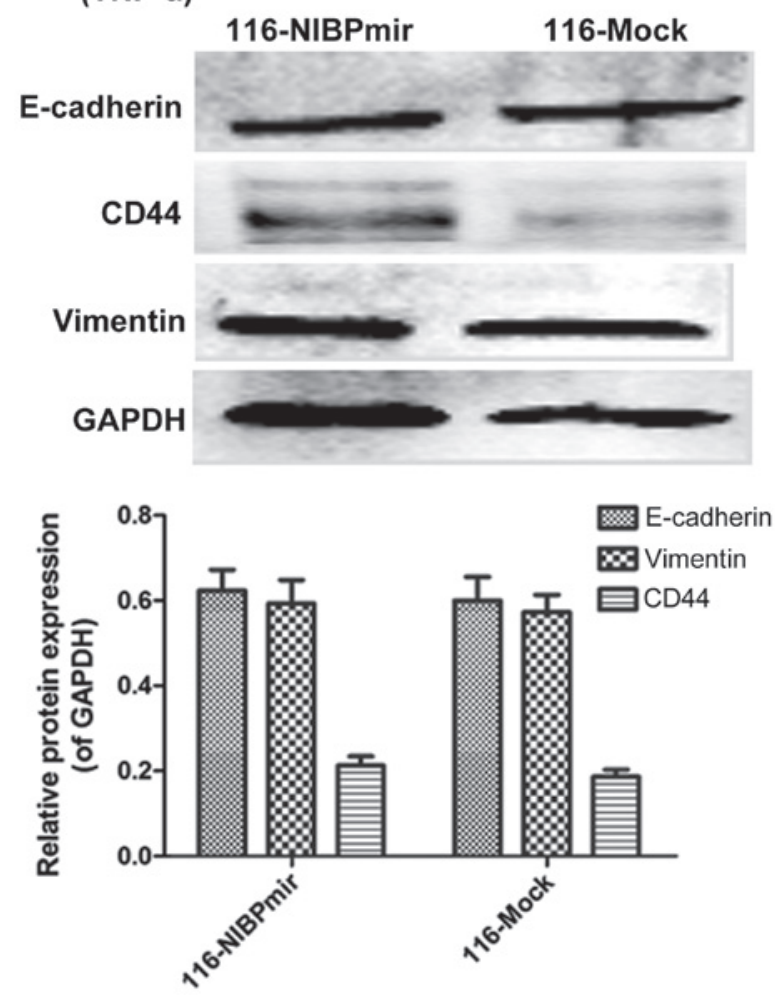

Figure 3. HCT116 cells (the 116-mock and 116-NIBPmir groups) were treated with TNF- $\alpha(20 \mathrm{ng} / \mathrm{ml})$ for $24 \mathrm{~h}$, and the expression levels of E-cadherin, CD44 and vimentin were analyzed by western blotting. GAPDH served as the loading control. The data were analyzed by t-test, which indicated there was no significant difference $(\mathrm{P}>0.05,116$-NIBP vs. the 116 -mock group TNF- $\alpha$, tumor necrosis factor- $\alpha$; GAPDH, glyceraldehyde-3-phosphate dehydrogenase.

that the expression of E-cadherin was markedly decreased, in accordance with the anticipated result. However, it was interesting to note that the expression levels of CD44 and vimentin were not significantly altered, demonstrating that NIBP predominantly regulated the NF- $\mathrm{kB}$ classical pathway, and exerted almost no influence on the alternative pathway in the absence of drugs to completely inhibit the classic pathway.

Furthermore, the cells were treated with PDTC to completely inhibit the NF-kB classical pathway. This revealed that the expression levels of CD44 and vimentin in the 29-NIBP group were also higher compared with the 29-mock group, suggesting that NIBP may be able to activate the alternative pathway when the classical pathway is blocked. Furthermore, the expression levels of E-cadherin in the 29-NIBP group were revealed to be lower compared with the 29-mock group, indicating that PDTC had failed to completely inhibit the NF- $\mathrm{KB}$ classical pathway when NIBP was upregulated in cells. These results, in part, may explain why certain previously published studies have shown that chemotherapeutic drugs, such as bortezomib and MLN120B, which predominantly suppress IKK $\beta$, one of the key factors of the NF- $\kappa B$ classical pathway, were also able to induce activation of NF- $\mathrm{KB}$ p65, leading to a poor curative response for patients $(36,37)$.

To further reveal the importance of NIBP in the NF- $\kappa B$ pathway, NIBP was knocked down in HCT116 cells, the highly aggressive colon cancer cell line. These results demonstrated that the expression of E-cadherin was increased, providing 
further evidence in support of the premise that NIBP predominantly regulates the $\mathrm{NF}-\kappa \mathrm{B}$ classical pathway in the absence of drugs which would block it, and that knocking down NIBP led to an inhibition of the classical pathway. Treating the cells with $\mathrm{TNF}-\alpha$, to induce the NF- $\kappa \mathrm{B}$ classical pathway, revealed a paralleled expression of E-cadherin, CD44 and vimentin in the 116-NIBPmir and 116-mock groups. These results demonstrated that TNF- $\alpha$ was able to impact on the NF- $\kappa \mathrm{B}$ classical pathway, although it was not able to influence the $\mathrm{NF}-\kappa \mathrm{B}$ alternative pathway when NIBP was silenced in cells, revealing that NIBP acts as the 'bridge' between the NF- $\kappa \mathrm{B}$ classical and alternative pathways.

In conclusion, the findings of the present study have revealed that upregulating the activity of NIBP leads to a regulation of the expression of E-cadherin, CD44 and vimentin in $\mathrm{CRC}$ via the $\mathrm{NF}-\kappa \mathrm{B}$ classical and alternative pathways. These findings have provided a possible rationale for the development of NIBP inhibitors, which may form part of the therapeutic regimen for patients with $\mathrm{CRC}$ in future.

\section{Acknowledgements}

This work was supported in part by grants from the National Natural Science Foundation of China (nos. 81260365 and 81460380), the Nature Science Foundation of Guangxi (no. 2013GXNSFAA019159) and the Traditional Chinese Medicine Ethnic Medicine Self-financing scientific research subject of Guangxi (no. GZZC14-57). Those responsible for funding this study had no involvement in study design, data collection or analysis, the decision to publish, or preparation of the manuscript.

\section{References}

1. Cancer Facts \& Figures 2015. American Cancer Society, 2015.

2. Wang F, Yang JL, Yu KK, Xu M, Xu YZ, Chen L, Lu YM, Fang HS,

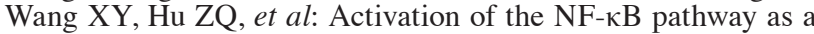
mechanism of alcohol enhanced progression and metastasis of human hepatocellular carcinoma. Mol Cancer 14: 10, 2015.

3. Zhao Z, Wu MS, Zou C, Tang Q, Lu J, Liu D, Wu Y, Yin J, Xie X, Shen J, et al: Downregulation of MCT1 inhibits tumor growth, metastasis and enhances chemotherapeutic efficacy in osteosarcoma through regulation of the NF- $\mathrm{BB}$ pathway. Cancer Lett 342: 150-158, 2014.

4. Zhang LL, Liu J, Lei S, Zhang J, Zhou W and Yu HG: PTEN inhibits the invasion and metastasis of gastric cancer via downregulation of FAK expression. Cell Signal 26: 1011-1020, 2014.

5. Perkins ND: Oncogenes, tumor suppressors and p52 NF-kappaB. Oncogene 22: 7553-7556, 2003.

6. Bonizzi $\mathrm{G}$ and Karin M: The two NF-kappaB activation pathways and their role in innate and adaptive immunity. Trends Immunol 25: 280-288, 2004.

7. Patke A, Mecklenbräuker I and Tarakhovsky A: Survival signaling in resting B cells. Curr Opin Immunol 16: 251-255, 2004.

8. Demchenko YN, Glebov OK, Zingone A, Keats JJ, Bergsagel PL and Kuehl WM: Classical and/or alternative NF-kappaB pathway activation in multiple myeloma. Blood 115: 3541-3552, 2010.

9. Hu WH, Pendergast JS, Mo XM, Brambilla R, Bracchi-Ricard V, Li F, Walters WM, Blits B, He L, Schaal SM and Bethea JR: NIBP, a novel NIK and IKK(beta)-binding protein that enhances NF-(kappa)B activation. J Biol Chem 280: 29233-29241, 2005.

10. Zhang Y, Bitner D, Pontes Filho AA, Li F, Liu S, Wang H, Yang F, Adhikari S, Gordon J, Srinivasan S and $\mathrm{Hu} \mathrm{W}$ : Expression and function of NIK- and IKK2-binding protein (NIBP) in mouse enteric nervous system. Neurogastroenterol Motil 26: 77-97, 2014.

11. Qin M, Liu S, Li A , Xu C, Tan L, Huang J and Liu S. NIK- and IKKbeta-binding protein promotes colon cancer metastasis by activating the classical NF-kappaB pathway and MMPs. Tumour Biol: Nov 23, 2015 (Epub ahead of print).
12. Thiery JP: Epithelial-mesenchymal transitions in tumour progression. Nat Rev Cancer 2: 442-454, 2002.

13. Thompson EW, Newgreen DF and Tarin D: Carcinoma invasion and metastasis: A role for epithelial-mesenchymal transition? Cancer Res 65: 5991-5995; discussion 5995, 2005.

14. Gujral TS, Chan M, Peshkin L, Sorger PK, Kirschner MW and MacBeath G: A noncanonical Frizzled2 pathway regulates epithelial-mesenchymal transition and metastasis. Cell 159: 844-856, 2014.

15. Tong W, Sun D, Wang Q and Suo J: Sorcin enhances metastasis and promotes epithelial-to-mesenchymal transition of colorectal cancer. Cell Biochem Biophys 2015 Jan 8, [Epub ahead of print].

16. Wang X, Wang H, Li G, Song Y, Wang S, Zhu F, Guo C, Zhang L and Shi Y: Activated macrophages down-regulate expression of E-cadherin in hepatocellular carcinoma cells via NF-kappaB/Slug pathway. Tumour Biol 35: 8893-8901, 2014.

17. Cheng ZX, Wang DW, Liu T, Liu WX, Xia WB, Xu J, Zhang YH, Qu YK, Guo LQ, Ding L, et al: Effects of the HIF- $1 \alpha$ and NF-kB loop on epithelial-mesenchymal transition and chemoresistance induced by hypoxia in pancreatic cancer cells. Oncol Rep 31: 1891-1898, 2014.

18. Li SY: NIBP expression in colorectal cancer tissues and its impact on colon cancer cell proliferation (unpublished $\mathrm{PhD}$ thesis). Guangxi Medical University, 2015.

19. Tan L: The research of NIBP protein expression and its relationship with the transformation of epithelial-mesenchymal in colorectal cancer tissue (unpublished $\mathrm{PhD}$ thesis). Guangxi Medical University, 2015.

20. Zheng L, Fu Y, Zhuang L, Gai R, Ma J, Lou J, Zhu H, He Q and Yang B: Simultaneous NF- $\kappa$ B inhibition and E-cadherin upregulation mediate mutually synergistic anticancer activity of celastrol and SAHA in vitro and in vivo. Int J Cancer 135: 1721-1732, 2014

21. Strippoli R, Benedicto I, Foronda M, Perez-Lozano ML, Sánchez-Perales S, López-Cabrera $\mathrm{M}$ and Del Pozo MÁ: p38 maintains E-cadherin expression by modulating TAK1-NF-kappaB during epithelial-to-mesenchymal transition. J Cell Sci 123: 4321-4331, 2010.

22. Zhang J, Yamada O, Kida S, Matsushita Y, Yamaoka S, Chagan-Yasutan $\mathrm{H}$ and Hattori T: Identification of CD44 as a downstream target of noncanonical NF- $\kappa$ B pathway activated by human T-cell leukemia virus type 1-encoded Tax protein. Virology 413: 244-252, 2011.

23. Päll T, Pink A, Kasak L, Turkina M, Anderson W, Valkna A and Kogerman P: Soluble CD44 interacts with intermediate filament protein vimentin on endothelial cell surface. PLoS One 6: e29305, 2011.

24. Steinmetz NF, Maurer J, Sheng H, Bensussan A, Maricic I, Kumar V and Braciak TA: Two domains of vimentin are expressed on the surface of lymph node, bone and brain metastatic prostate cancer lines along with the putative stem cell marker proteins CD44 and CD133. Cancers (Basel) 3: 2870-2885, 2011

25. Mashita N, Yamada S, Nakayama G, Tanaka C, Iwata N, Kanda M, Kobayashi D, Fujii T, Sugimoto H, Koike M, et al: Epithelial to mesenchymal transition might be induced via CD44 isoform switching in colorectal cancer. J Surg Oncol 110: 745-751, 2014.

26. Suzuki Y, Yamaguchi T, Matsumoto H, Nakano D, Honda G, Shinoura N, Karasawa K and Takahashi K: Prognostic factors and treatment effects in patients with curatively resected brain metastasis from colorectal cancer. Dis Colon Rectum 57: 56-63, 2014.

27. Wein A, Emmert M, Merkel S, Harich HD, Siebler J, Thiemann R, Lamberti C, Göttler B, Fries S, Kiani A, et al: Palliative treatment of colorectal cancer with secondary metastasis resection in Germany-impact of the multidisciplinary treatment approach on prognosis and cost: The Northern Bavaria IVOPAK I Project. Oncology 88: 103-121, 2015.

28. Chaw SY, Majeed AA, Dalley AJ, Chan A, Stein S and Farah CS: Epithelial to mesenchymal transition (EMT) biomarkers-E-cadherin, beta-catenin, APC and Vimentin-in oral squamous cell carcinogenesis and transformation. Oral Oncol 48: 997-1006, 2012.

29. Zhai X, Zhu H, Wang W, Zhang S, Zhang Y and Mao G: Abnormal expression of EMT-related proteins, S100A4, vimentin and E-cadherin, is correlated with clinicopathological features and prognosis in HCC. Med Oncol 31: 970, 2014. 
30. Takahashi Y,Sawada G,Kurashige J,Uchi R, Matsumura T, Ueo H, Takano Y, Akiyoshi S, Eguchi H, Sudo T, et al: Paired related homoeobox 1, a new EMT inducer, is involved in metastasis and poor prognosis in colorectal cancer. Br J Cancer 109: 307-311, 2013.

31. Rokavec M, Öner MG, Li H, Jackstadt R, Jiang L, Lodygin D, Kaller M, Horst D, Ziegler PK, Schwitalla S, et al: IL-6R/STAT3/miR-34a feedback loop promotes EMT-mediated colorectal cancer invasion and metastasis. J Clin Invest 124: 1853-1867, 2014

32. Zhang L, Shao L, Creighton CJ, Zhang Y, Xin L, Ittmann M and Wang J: Function of phosphorylation of NF-kB p65 ser536 in prostate cancer oncogenesis. Oncotarget 6: 6281-6294, 2015.

33. Yu H, Shen Y, Hong J, Xia Q, Zhou F and Liu X: The contribution of TGF- $\beta$ in epithelial-mesenchymal transition (EMT) Down-regulation of E-cadherin via snail. Neoplasma 62: 1-15, 2015.
34. Ji Q, Liu X, Han Z, Zhou L, Sui H, Yan L, Jiang H, Ren J, Cai J and Li Q: Resveratrol suppresses epithelial-to-mesenchymal transition in colorectal cancer through TGF-beta1/Smads signaling pathway mediated Snail/E-cadherin expression. BMC Cancer 15: 97, 2015.

35. Du L, Rao G, Wang H, Li B, Tian W, Cui J, He L, Laffin B, Tian X, Hao C, et al: CD44-positive cancer stem cells expressing cellular prion protein contribute to metastatic capacity in colorectal cancer. Cancer Res 73: 2682-2694, 2013.

36. Li C, Chen S, Yue P, Deng X, Lonial S, Khuri FR and Sun SY: Proteasome inhibitor PS-341 (bortezomib) induces calpain-dependent IkappaB(alpha) degradation. J Biol Chem 285: 16096-16104, 2010.

37. Hideshima T, Chauhan D, Kiziltepe T, Ikeda H, Okawa Y, Podar K, Raje N, Protopopov A, Munshi NC, Richardson PG, et al: Biologic sequelae of IkappaB kinase (IKK) inhibition in multiple myeloma: Therapeutic implications. Blood 113: 5228-5236, 2009. 